NOTA CIENTÍFICA

\title{
Hongos filamentosos con actividades ligninolíticas aislados de Calamagrostis nitidula Pilg. Lignin-degrading filamentous fungi isolated from Calamagrostis nitidula Pilg.
}

\author{
Janet Laura y Pedro Castellanos
}

Facultad de Ciencias Biológicas, Universidad Nacional Mayor de San Marcos, Av. Venezuela cdra. $35 \mathrm{~s} / \mathrm{n}$ Ciudad Universitaria, Apartado 110058, Lima 11, Perú. Email tado 110058, Lima 11, Perú. Email unmsm.edu.pe

Presentado: 26/01/2008 Aceptado: 02/03/2009 Publicado online: $28 / 08 / 2009$

\section{Resumen}

Hongos con actividad ligninolitica fueron aislados de la planta forrajera Calamagrostis nitidula Pilg. (Poaceae). Se utilizo el medio mínimo Czapeck conteniendo lignina $(0,2 \%)$ como única fuente de carbono, los medios fueron inoculados con fracciones de $C$. nitidula. Posteriormente los hongos desarrollados fueron aislados en agar papa dextrosa (APD) e identificados según sus características macroscópicas y microscópicas. Se aislaron e identificaron los siguientes géneros: Alternaria, Ulocladium, Trichoderma, Cephalosporium, Helicomyces, Mucor y Aspergillus. La capacidad de degradación de lignina fue determinada cualitativamente y cuantitativamente, inoculando cada cepa obtenida en tubos con caldo Czapeck con $0,2 \%$ de lignina y $1 \%$ de glucosa. La cepa PD5F identificada como Aspergillus melleus Yukawa fue la única con actividad ligninolitica.

Palabras claves: Degradación ligninolítica, Calamagrostis nitidula, Aspergillus melleus, lignina, ligninasas.

\section{Abstract}

We isolated fungi with ligninolytic activity of the forage plant Calamagrostis nitidula Pilg. (Poaceae). The minimum Czapeck medium containing lignin $(0,2 \%)$ as carbon source, was inoculated with fractions of $C$. nitidula. Subsequently, the fungus developed were isolated in potato dextrose agar (PDA) and identified according to their macroscopic and microscopic characteristics. The following genus were isolated and identified: Alternaria, Ulocladium, Trichoderma, Cephalosporium, Helicomyces Mucor and Aspergillus. Degradation of lignin was determined qualitatively and quantitatively, by inoculating each strain obtained in tubes with Czapeck medium with $0,2 \%$ lignin and $1 \%$ glucose. Only the PD5F strain identified as Aspergillus melleus Yukawa was ligninolytic activity.

Keywords: ligninolytic degradation, Calamagrostis nitidula, Aspergillus melleus, Lignin, ligninases.

\section{Introducción}

La lignina es un polímero complejo conocido por su resistencia al ataque microbiano y es considerado como un componente anticalidad por su impacto negativo en la disponibilidad nutricional de la fibra de la planta (Moore y Jung 2001). Los hongos con actividades ligninolíticas se vienen estudiando desde hace dos décadas en "pajas", como las de trigo, la cascarilla de arroz y en madera (Steffen et al. 2002). Estos hongos pertenecen a la clase basidiomycetes, pero también han sido reportados Ascomycetes y Levaduras (Milstein et al. 1983, Kadam y Drew, 1985, Betts y Dart 1989, Cardoso y Costa 1994, Conesa et al. 1999, Steffen et al. 2002, Olvera 2003)

El Perú cuenta con una diversidad de pastizales silvestres nativos (pastos forrajeros) pertenecientes a la familia Poaceae (gramíneas) que crecen en altitudes por encima de 3500-3800 m de altitud, sobre todo en la región alto andina; entre los cuales, los llamados "pajonales" ocupan áreas extensas y están formados por especies de los géneros Stipa, Festuca y Calamagrostis. Estas comunidades de plantas son las únicas fuentes de alimento para la ganadería de las zonas alto andinas teniendo un bajo valor nutritivo ( $5 \%$ de proteína y $35,4 \%$ de fibra cruda) y baja digestibilidad debido a la lignina (Choque y Sotomayor 1989, Tovar 1960, 1993, Didier et al. 1994).

En el presente trabajo se aíslan, identifican y evalúan hongos ligninolíticos a partir de Calamagrostis nitidula.

\section{Materiales y métodos}

\section{Recolección de muestra vegetal}

Muestras de paja silvestre de Calamagrostis nitidula Pilg. en condición erguida (PE) y descompuesta (PD) fueron recolectadas en la localidad de Ticlio, provincia de Huarochiri, departamento de Lima a $4800 \mathrm{~m}$ de altitud.
El material biológico recolectado se guardó en una prensa de madera entre secantes. Para su identificación se siguió la clave dicotómica de Tovar (1960, 1993).

\section{Aislamiento de los hongos de Calamagrostis nitidula}

Las muestras colectadas de Calamagrostis nitidula fueron procesadas en el laboratorio el mismo día de la colecta, se cortó en trozos pequeños y se sembró en medio líquido de sales minerales Czapeck teniendo a la lignina como única fuente de carbono $0,2 \%$ (Lignin álcali low sulfonate content, ALDRICH). El medio líquido Czapeck-Lignina fue llevado a un $\mathrm{pH} 5,5$, a una temperatura de laboratorio de $25^{\circ} \mathrm{C}$ y una humedad relativa de $65 \%$, en cultivos sumergidos estáticos y en oscuridad. Los cultivos líquidos fueron evaluados durante 30 días. Una vez observado el crecimiento superficial y la producción de gas se tomó un inóculo de cada frasco y se sembró en placas petri conteniendo Agar Czapeck-Lignina al 0,2\%, a pH 5,5. Las colonias aisladas fueron sembradas en placas petri con un medio de agar papa dextrosa (APD) observándose diariamente su crecimiento hasta los 20 días para luego obtener un cepario.

\section{Identificación de los hongos aislados}

Se observaron características macroscópicas de las colonias describiendo detalles de textura, aspecto, superficie, color en un estereoscopio. También se realizó la observación microscópica mediante la técnica de microcultivo en lámina para observar las estructuras vegetativas y reproductivas. En la identificación de género y especie se utilizó el manual de identificación de hongos según Egorova (1983).

\section{Prueba de la degradación de la lignina}

Las concentraciones de la lignina fueron medidas por su absorbancia a $560 \mathrm{~nm}$ en un espectrofotómetro estableciéndose una curva de calibración (Olvera 2003) (Fig. 1). 


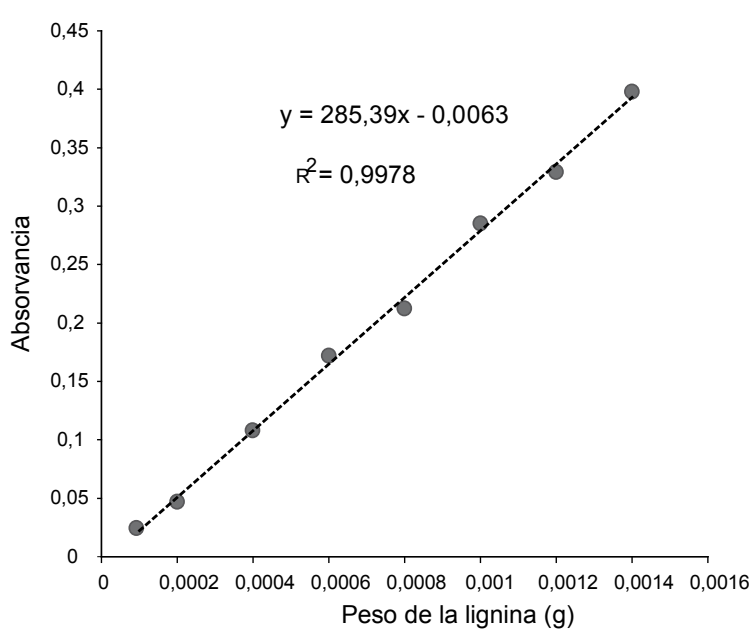

Figura 1. Curva de calibración para medir la concentración de la lignina vs la absorbancia a $560 \mathrm{~nm}$ del medio de cultivo.

Las cepas aisladas se sembraron en el medio Czapeck con 0,002 g/mL de lignina y 3 blancos con medio Czapeck sin lignina ambos por triplicado. Las muestras fueron incubadas en condiciones de laboratorio a una temperatura de $25^{\circ} \mathrm{C}$, humedad relativa de $65 \%$. Los cultivos de las cepas fueron sometidas a dos procesos fermentativos: el primero, un cultivo en condiciones estáticas por 15 días y el segundo fue incubado en un agitador orbital por 7 días a 150 RPM. En la determinación del consumo de la lignina se utilizaron dos métodos: a) Método cualitativo y b) Método cuantitativo.

\section{a) Método cualitativo}

Se evaluó diariamente el cambio de la coloración café de la lignina contenida en los matraces hasta 30 días. Al cabo de este tiempo se filtró con papel filtro de 4-7 micras (filtración lenta), para retener las esporas, luego se hizo una centrifugación a 5300 RPM por 30 minutos para separar el resto de micelio.

\section{b) Método cuantitativo}

Se tomó $10 \mathrm{~mL}$ del filtrado de las muestras tratadas en el método cualitativo y se procedió a medir la absorbancia de cada tubo a $560 \mathrm{~nm}$, determinándose el peso soluble de lignina en el medio de cultivo, luego se calculo la cantidad de lignina degradada por el hongo.

\section{Resultados y discusión}

\section{Aislamiento e identificación de los hongos ligninolíticos}

Doce cepas de hongos filamentosos tanto en paja erguida (PE) como paja descompuesta (PD) fueron aislados (Tabla 1).

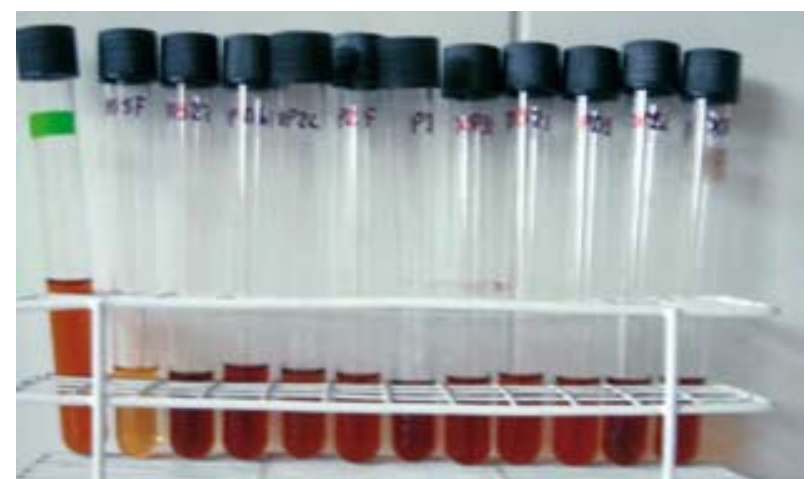

Figura 2. Prueba cualitativa de la degradación de lignina. Obsérvese que el segundo tubo (Cepa PD5F) identificado como Aspergillus melleus Yukawa ha sido el único que ha virado de color.
Tabla 1. Cepas fúngicas aisladas de Calamagrostis nitidula Pilger.

\begin{tabular}{|c|c|c|}
\hline Tipo de paja & Cepas fúngicas aisladas & Géneros \\
\hline \multirow{5}{*}{ 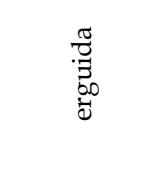 } & $\mathrm{P} 2 \mathrm{C}$ & Alternaria sp. \\
\hline & $\mathrm{P} 2 \mathrm{~F}$ & Ulocladium sp. \\
\hline & P3C & Alternaria sp. \\
\hline & P3E & Trichoderma sp. \\
\hline & PD1F & Mucor sp. \\
\hline \multirow{7}{*}{ 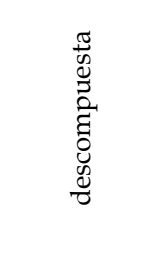 } & PD321 & Helicomyces sp. \\
\hline & PD322 & Trichoderma sp. \\
\hline & PD3S & Cephalosporium sp. \\
\hline & PD3 & Cephalosporium sp. \\
\hline & PD5F & Aspergillus melleus \\
\hline & PD6C & Cephalosporium sp. \\
\hline & PD6F & Cephalosporium sp. \\
\hline
\end{tabular}

* $(\mathrm{PE})$ : paja erguida y $(\mathrm{PD})$ muestra de paja descompuesta.

En el medio Czapeck con lignina todas estas cepas formaron colonias levaduriformes, sin embargo, al sembrarlas en APD tomaron las características propias filamentosas según el género de los hongos.

\section{Degradación de la lignina por los hongos aislados}

La prueba de degradación de lignina se realizó con las 12 cepas aisladas de las diferentes muestras de paja a partir de un inóculo de cada una en el medio mínimo Czapeck con glucosa al 1\% y lignina al 0,2\%. Después de 15 días en cultivo estático, la cepa PD5F fue la única que evidencio la degradación de la lignina, al cambiar de un color café a un color amarillo (Fig 2). En la evaluación cuantitativa la cepa PD5F mostró una absorbancia final de 0,118 con respecto al blanco 0,631 , lo cual indicó una degradación de 0,002 a $0,0004 \mathrm{~g} / \mathrm{mL}$ de lignina al cabo de 15 días, lo que corresponde a una degradación del $80 \%$. En la prueba cualitativa en un cultivo en agitación, se pudo observar un cambio de coloración en la cepa PD5F a los 7 días de crecimiento. El resto de cepas no evidenció cambios en la coloración del caldo de cultivo, pero si se observó crecimiento, y al realizar la determinación cuantitativa se observa en algunas cepas un incremento de la absorbancia en relación al blanco, esto se debe a que los hongos han producido pigmentaciones en el medio de cultivo, alterando la lectura del espectrofotómetro (Fig.3).

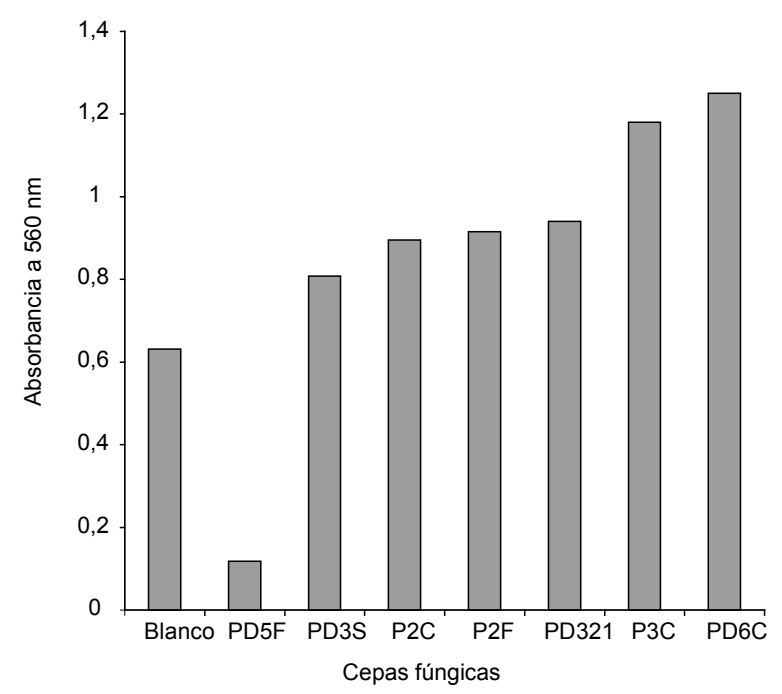

Figura 3. Cuadro comparativo de la absorbancia de la lignina después del periodo de cultivo de las cepas fúngicas aisladas de Calamagrostis nitidula Pilger. 


\section{Identificación de la cepa PD5F con actividades lignino- liticas}

La cepa PD5F fue identificada hasta especie como Aspergillus melleus Yukawa (Egorova 1986), y esta caracterizada por tener abundante micelio, semejante a césped, abundantes cabezas conidiales dorada-amarillentas; el lado reverso es rojo-castaño. La cabeza aspergilar es esférica de 140,8 micras de diámetro y tiende a elongarse en forma de columnas. La vesícula tiene un promedio de 53,5 micras de diámetro. Las hifas vegetativas son hialinas y septadas. El conidióforo es amarillo y rugoso, lleva métulas y fiálides con conidias de paredes lisas de 1,92-2,4 micras.

\section{Discusión}

En la primera prueba espectrofotométrica donde se utilizó el medio mínimo Czapeck y lignina al 0,2\%, no mostró un adecuado crecimiento ni variación de coloración, por lo tanto al medio utilizado se le ańadió glucosa al $1 \%$, porque la degradación de la lignina se da con el consumo previo de la glucosa según los trabajos realizados por Lobarzewski y Paszczynski (1985) y Olvera (2003).

De todos los hongos filamentosos aislados, únicamente Aspergillus melleus cambió la coloración de la lignina en medio agitado a 150 RPM al cabo de 7 días, y en condiciones estáticas se evidencio la degradación de lignina de este hongo a los 15 días de incubación. La diferencia en el tiempo del cambio de coloración se debe a que el proceso degradativo de la lignina es oxidativo, y es necesario la presencia de oxigeno (Olvera, 2003). La lignina tiene un color café debido a grupos cromóforos fuertemente unidos a la molécula, para que se reduzca este color es necesario la presencia de oxigeno y peroxido de hidrogeno, el proceso oxidativo causa la ruptura de los enlaces insaturados carbono-carbono de las cadenas propanoides destruyendo algunos grupos cromóforos (Lin, 1980). Por lo tanto, aireación, presencia de oxigeno y dosis adecuada de glucosa permiten la degradación de la lignina al cabo de 7 días, previo consumo de la glucosa (Lobarzewski y Paszczynski 1985, Olvera 2003). También es de notar que las enzimas son expresadas durante la fase secundaria del crecimiento (idiofase) cuando la limitación de carbono, nitrógeno y sulfuro ocurre (Staszczak, 2002); sin embargo es necesario realizar estudios para evaluar que tipo de enzima esta actuando.

Estos hongos no pueden utilizar directamente lignina como su fuente de carbono y energía por ello dependen de azucares más digeribles como los monómeros precursores de fenilpropano. La función primaria de la ligninólisis es exponer estos monómeros al ataque del hongo con ayuda de diferentes tipos de enzimas. En la mayoría de los hongos se ha observado que la lignólisis ocurre durante el metabolismo secundario, es decir bajo limitación de nutrientes, lo que permite que el hongo solo sintetice y secrete agente ligninolíticos que comiencen a fragmentar el polímero (Olvera 2003, Lobarzewski y Paszczynski 1985).

Los otros hongos aislados mostraron un crecimiento muy notable en los medios Czapeck-Lignina con glucosa al 1\%, esto se debió al consumo preferencial de la glucosa y en consecuencia no tendrían el potencial enzimático adecuado para transformar la lignina al cabo de un mes en condiciones estáticas y al cabo de 15 días en condiciones agitadas de 150 RPM. Otra observación, fue el aumento de la absorbancia al inicio del experimento en algunas cepas, esto se explica debido a que los hongos aislados presentaron pigmentación en el medio debido al crecimiento lo cual influyo sobre la absorbancia.

Aspergillus melleus es un hongo ligninolítico productor de micotoxinas y de enzimas tales como proteasas, esterasas, (Semeniuk et al. 1971, Palumbo et al. 2007, Ondeyka et al. 2003, Luisetti et al. 1991, Miyazawa et al. 2002) aunque no hay registros de su actividad ligninolítica en la literatura, en este trabajo se ha demostrado su capacidad en la degradación de la lignina.

Por otro lado, el medio empleado Czapeck-Lignina tenía elementos químicos como nitrógeno, sodio, potasio, cloro, fosfatos, sulfatos, magnesio y Hierro, pese a esto Aspergillus melleus fue capaz de degradar la lignina en el caldo de cultivo, aun no habiendo manganeso ni cobre que son los elementos necesarios. Se ha señalado que para que se active las enzima MnP y la lacasa tienen que tener concentraciones de $\mathrm{Mn}$ (II) y Cu minimas, en caso contrario no se detectaría la actividad de estas isoenzimas (Polanco et al. 2002, Staszczak 2002).

\section{Agradecimientos}

Al Dr. Juan Sabatier Cadalso por el valioso asesoramiento. Al Dr. Oscar Tovar y la Magíster Maria Isabel La Torre, quienes ayudaron en la identificación del material botánico en el Herbario de San Marcos (UNMSM).

\section{Literatura citada}

Betts W. \& R. Dart. 1989. Initial reactions in degradation of tri- and tetrameric lignin-related compounds by Aspergillus flavus. Mycological Research 92(2):177-181.

Cardoso J. \& M. Costa. 1994. Aspergilli and lignocellulosics: Enzymology and biotechnological applications. Microbiology Reviews 13(2-3):377-386.

Conesa A., C. Hondel \& P. Punt. 2000. Studies on the Production of Fungal Peroxidases in Aspergillus niger. Appl. Environ. Microbiol 66(7): 3016-3023.

Choque L. y M. Sotomayor. 1989. Resúmenes de investigación en pastos y forrajes de la region sur peruana. Proyecto Alpacas. Universidad Nacional del Altiplano.181 pp.

Didier G., Z. Villca \& P. Abasto.1994. Diet selection and utilization by llama and sheep in a high altitude-arid rangeland of Bolivia. Journal of Range Management 47:245-248.

Egorova, L.1986. Hongos del suelo. Instituto de biología del suelo de la Academia de Ciencias. URSS. Editorial "Ciencia", División de Leningrado. 207pp. (En Ruso)

Kadam K. \& S. Drew. 1985. Study of lignin biotransformation by Aspergillus fumigatus and white-rot fungi using 14Clabeled and unlabeled kraft lignins. Biotechnology and Bioengineering 28(3): 394-404.

Lin, S. 1980. Process for reduction of lignin color. U. S.Patent 4184845. <http://www.freepatentsonline.com/4184845. html

Lobarzewski J. \& A. Paszczynski. 1985. Lignocellulose biotransformation with inmobized Cellulose D-glucose oxidase and fungal peroxidases. Enzyme and Microbial Technology (7) 564-566.

Luisetti M., P. Piccioni, K. Dyne, M. Donnini , A. Bulgheroni, et al. 1991. Some properties of the alkaline proteinase from Aspergillus melleus. Int. J. Tissue React. 13(4):187-192.

Milstein O., Y. Vered, L. Shragina, J. Gressel, H. Flowers \& A. Hüttermann. 1983. Metabolism of lignin related aromatic compounds by Aspergillus japonicus. Archives of Microbiology 135(2). 
Miyazawa T., M. Hiramatsu, T. Murashima \& T. Yamada. 2002. Aspergillus melleus protease-catalyzed peptide synthesis using the carbamoylmethyl ester as an acyl donor in 1,1,1,3,3,3-hexafluoro- 2-propanol/N,N-dimethylformamide. Biotechnology Letters. 24(23): 1945-1949.

Moore K. \& H. Jung. 2001. Lignin and fiber digestion. Journal of range management 54:420-430.

Ondeyka J., A. Dombrowski, J. Polishook, T. Felcetto, W. Shoop, et al. 2003. Isolation and insecticidal activity of mellamide from Aspergillus melleus. Journal of Industrial Microbiology and Biotechnology 30(4):220-224.

Olvera P. 2003. Aislamiento de levaduras que tengan la capacidad para degradar lignina y búsqueda de algunos genes implicados en dicha degradación. Tesis profesional presentada para obtener el titulo en maestría en biotecnología. Escuela de Ciencias, Universidad de las Américas. Puebla-México.

Palumbo J., T. O'Keeffe \& N. Mahoney. 2007. Inhibition of ochratoxin A production and growth of Aspergillus species by phenolic antioxidant. Mycopathologia 164(5):241-248.
Polanco R., S. Lobos y R. Vicuña. 2002. Binding of nuclear proteins to the promoter region of the laccase gene Cs-lcs1 from the basidiomycete Ceriporiopsis subvermispora. Enzyme and Microbial Technology 30:525-528.

Semeniuk G. G. S. Harshfield, C. W. Carlson, C. W. Hesseltine, \& W. F. Kwolek. 1971. Mycotoxins in Aspergillus. Mycopathologia. 43(2):137-152.

Staszczak M. 2002. Proteasomal degradation pathways in Trametes versicolor and Phlebia radiata. Enzyme and Microbial Technology 30: 537-541.

Steffen K., M. Hofrichter \& A. Hatakka. 2002. Purification and characterization of manganese peroxidase from the litterdecomposing basidiomycetes Agrocybe praecox and Stropharia coronilla. Enzyme and Microbial Technology 30:550-555.

Tovar O. 1960. Revisión de las especies peruanas del género Calamagrostis. En: memorias del museo de Historia Natural "Javier Prado" N0 II, 1960.

Tovar O. 1993. Las gramíneas (Poaceae) del Perú. Madrid, Real Jardín Botánico de Madrid. 